\title{
Moda (in)sustentável?
}

(Un)sustainable fashion?

Paula Piva Linke

Unifamma

paulapivalinke@gmail.com

X

PROJËTICA

\section{COMO CITAR ESTE ARTIGO:}

LINKE, Paula Piva. Moda (in)sustentável? Projética, Londrina, v. 12, n. 2, p. 39-69, 2021.

DOI: 10.5433/2236-2207.2021v12n2p39

Submissão: 01-07-2020

Aceite: 21-01-2021 
RESUMO: Pensar a moda na atualidade requer olhá-la em diversos ângulos, inclusive no que se refere à questão ambiental. Um dos assuntos que merece destaque é certamente a reflexão sobre moda e sustentabilidade, principalmente em se tratando do fato de que a moda, em muitos momentos é vista como frívola e efêmera. Esse artigo tem como objetivo traçar uma discussão acerca da moda e da sustentabilidade e está dividido em três partes, incluindo a introdução e as considerações finais. Apresentamos inicialmente o conceito de Moda, em seguida uma discussão sobre o conceito de sustentabilidade e, por fim, estabelece-se a relação entre moda e sustentabilidade. Em se tratando da relação ambiente e sociedade, a moda não pode ser considerada sustentável, pois sobrevive do consumo e o incita por meio da mudança de tendências. A moda deve ser concebida como um fenômeno que impacta de forma negativa o ambiente, mas que pode apresentar práticas menos impactantes.

Palavras-chave: Moda. Sustentabilidade. Ambiente.

ABSTRACT: Thinking about fashion today requires looking at it from several perspectives, including what relates to environmental issues. One of the issues worth mentioning is certainly the reflection on fashion and sustainability, especially regarding the fact that fashion, in many instances, is seen as frivolous and ephemeral. This article aims to outline a discussion about fashion and sustainability and is divided into three parts, including introduction and closing remarks. We initially present the concept of fashion, then a discussion on the concept of sustainability and, finally, we establish the relationship between fashion and sustainability. In terms of the relationship between environment and society, fashion cannot be considered sustainable because it depends on consumption and pushes on consumption according to the changing of trends. Fashion should be seen as a phenomenon that negatively impacts the environment, but which could have less impactful practices.

Keywords: Fashion. Sustainability. Environment. 


\section{INTRODUÇÃO}

A crise ambiental se apresenta de forma complexa e envolve toda a sociedade, não apenas os setores produtivos e o consumo, refletindo a forma como temos vivido e como temos cuidado do meio ambiente. No que se refere à sustentabilidade, ou mesmo ao desenvolvimento sustentável, conceitos que surgem com o objetivo de promover a manutenção do capital natural ainda geram muitos questionamentos.

Nesse sentido, um dos assuntos que merece destaque é certamente a reflexão acerca da moda e da sustentabilidade, levando-nos a questionamentos e indagações sobre essa relação. Tal reflexão faz parte de uma pesquisa de doutorado ainda em desenvolvimento relacionada ao tema.

Para melhor compreensão do assunto, dividiu-se o artigo em três partes. Inicialmente, apresenta-se o conceito de Moda, relacionando-o aos sistemas produtivos e alguns de seus impactos ao meio ambiente. Para traçar a conceituação do termo moda, amparamo-nos teoricamente nos conceitos postulados por Lipovetsky (1989), e Sorcinelli (2008). Para tratarmos dos conceitos acerca dos problemas ambientais utilizamos Berlim (2012), Fletcher e Grose (2011).

Em seguida, apresenta-se uma discussão sobre o conceito de sustentabilidade, discutindo as diversas concepções que o conceito carrega e as particularidades do mesmo. Para a conceituação, utilizaremos May, Lustosa e Vinha (2003), Kuhlman e Farington (2010), Talmasquim (2003). Faremos o uso dos conceitos postulados por Leff (2012) para algumas reflexões acerca da vulgarização do conceito "sustentabilidade".

Por fim, relacionaremos moda e sustentabilidade apontando alguns questionamentos pertinentes que conduzam a uma reflexão mais intensa sobre o tema abordado. Para dar suporte e fundamentação teórica para o tema abordado, utilizaremos autores como Berlim (2012), Manzini e Vezzoli (2010), Zanirato (2013). 
Projética, Londrina, v. 12, n. 2, p. 39-69, agosto 2021

\section{MODA}

Pensar a moda na atualidade não é uma tarefa fácil, pois a mesma carrega consigo uma série de implicações que não se refletem somente à ordem estética, mas envolvem outros setores como o cultural, social, político, econômico e também o ambiental.

A moda é um fenômeno que envolve séculos de história. A concepção de Moda surge no final da Idade Média, momento em que se inicia um processo de mudança na forma de se vestir (LIPOVETSKY, 1989).

No entanto, é no século XVIII que a moda começa a se manifestar com maior intensidade, principalmente por meio da influência do Rei Luiz XIV da França. Somente no século XIX, período que marca o surgimento da Alta Costura, é que a moda se desenvolve como a conhecemos hoje, surgindo a figura do estilista ou criador de moda e dos desfiles (LIPOVETSKY, 1989).

Em outras palavras, podemos compreender a moda como "um costume presente em certas sociedades, para qual as roupas, os acessórios, os objetos, as tendências culturais renovam-se ciclicamente por meio de formas comuns" (SORCINELLI, 2008, p. 158).

A definição de Sorcinelli (2008) parece aparentemente simplista, mas expressa a essência e, ao mesmo tempo, a complexidade do conceito. Primeiramente, convém ressaltar que a autora, ao ressaltar a expressão "presente em certas sociedades", aponta para o surgimento da moda como sendo um fenômeno ocidental e que não se desenvolveu no mundo todo, mas se difundiu especificamente no Ocidente e a partir de seu surgimento, foi aos poucos, se difundindo para o Oriente (LIPOVETSKY, 1989). 
O fenômeno da moda não abarca somente a esfera do vestuário, embora esse seja o seu maior representante, mas engloba outros setores como o mobiliário, a arquitetura, a estética, a arte entre outros. Nesse sentido, há de se destacar a renovação das tendências culturais. Assim sendo, pode-se entender a moda como "fenômeno social da mudança cíclica dos costumes e dos hábitos, das escolhas e dos gostos, coletivamente validado e tornado quase obrigatório" (CALANCA, 2008, p. 11-12).

O conceito de moda apresenta-se de forma multifacetada ao abarcar vários elementos relacionados a uma sociedade, como cultura, classes sociais e política, por exemplo, assim como uma circulação daquilo que é ou não aceito e validado como moda.

Mesmo que alguns autores se esforcem para delimitar a moda, conceituála ou defini-la, Sorcinelli (2008) ressalta o vocábulo moda tornou-se banal, uma representação social, ao ser incorporado no imaginário coletivo. Para a autora, o termo moda transformou-se em um termo "abrange tudo" relacionado ao corpo e ao vestuário. "É sinônimo de estilo, modo de vestir, costume, que afinal de contas não corresponde a nenhum significado específico" (SORCINELLI, 2008, p. 48).

A afirmação de Sorcinelli (2008) soa um tanto quanto exagerada, chamando a atenção para o fato de que a moda abrange não somente a esfera do parecer, mas circula na esfera social, cultural, política, econômica, manifestando-se de formas diversas nas mais variadas esferas e setores sociais. Moda, nessa concepção, é uma representação social, um fenômeno que participa do cotidiano do indivíduo, construindo seu entendimento sobre esse assunto por meio de informações e fontes diversas.

Logo, quando pensamos em vestuário, o termo moda nos vem à cabeça, assim como a frivolidade. No entanto, por trás da moda, existe o objeto roupa, 
e esse objeto torna-se um produto que carrega consigo uma carga simbólica, as tendências e o próprio conceito de "estar ou não na moda". Por meio dessa ideologia, existe um universo extremamente complexo que produz a roupa, transformando-a em um objeto de desejo e para o qual a indústria terá um papel determinante.

O século XX marcou a história da produção de roupas e também da moda, pois efetivou a indústria têxtil por meio do sistema de produção em massa, criando o setor da confecção. Formou-se aí uma duplicidade na concepção da moda. "De um lado temos o crescente desenvolvimento da indústria e a criação de tendências que geram mudanças significativas no design da roupa (seu feitio, material e durabilidade)" (BERLIM, 2012, p. 20). Por outro, temos a moda como responsável por essa indústria, que apresenta duas importantes facetas: "a do produto (roupas e acessórios) e a do conceito gerador de tendências, que expressa nossas necessidades emocionais e psicológicas" (BERLIM, 2012, p. 20).

Essas necessidades são sanadas pelo consumo desses produtos que, após saírem de moda, são descartados, surgindo a necessidade de se criar uma peça que substitua a anterior. Desse modo, a vida útil desses produtos não está relacionada à durabilidade ou utilidade da peça, mas à estética, ao julgo alheio de pertença ou não da moda. Dessa feita, a moda sobrevive do consumo, alimenta-se dele, encontrando vida no lançamento de novas tendências.

Portanto, faz-se necessário compreender a moda como um fenômeno de mudanças cíclicas que influencia não somente as tendências do vestuário, mas a arquitetura, carros, mobiliário, decoração, englobando as diversas atividades produtivas e culturais na qual o design está presente. A moda, além de abarcar diferentes setores produtivos e de consumo, atinge, também, a sociedade e o ambiente. 
Faz-se necessário compreender a moda como um fenômeno de mudanças cíclicas que influencia não somente as tendências do vestuário, mas a arquitetura, carros, mobiliário, decoração, englobando as diversas atividades produtivas e culturais na qual o design está presente. A moda, além de abarcar diferentes setores produtivos e de consumo, atinge, também, a sociedade e o ambiente.

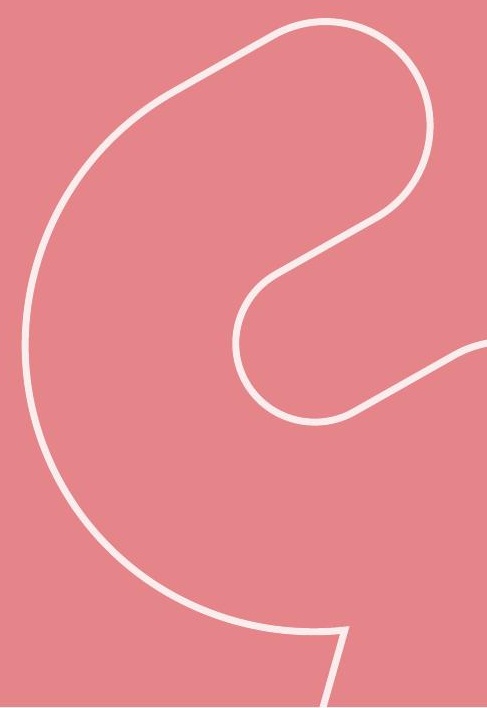


Nesse sentido, alguns questionamentos são necessários para que possamos compreender a complexidade da moda: como a moda se comporta em relação ao meio ambiente? Existe e/ou é possível existir relação ente moda e sustentabilidade? O que é sustentabilidade? Estas indagações suscitaram a escrita deste artigo, pois as consideramos fundamentais para a reflexão da moda. Vejamos a seguir a concepção de sustentabilidade para então prosseguirmos a discussão sobre moda e sustentabilidade.

\section{SUSTENTABILIDADE}

Os problemas ambientais atuais gerados pelo sistema capitalista exigem novos olhares sobre o meio ambiente. Todos esses impasses exigem outra postura da sociedade atual, defendida como sociedade sustentável. Mas o que seria sustentabilidade? É possível alcançá-la dentro de uma realidade em que a racionalidade econômica impera?

Em seu livro, Saber Ambiental, Leff (2012) apresenta uma discussão acerca da problemática ambiental contemporânea, debatendo conceitos, paradigmas e apontando a necessidade de substituição de uma racionalidade econômica por uma racionalidade ambiental. Nesta racionalidade, a problemática ambiental está posta e requer posições diferenciadas das que temos no mundo da certeza e da simplificação racional e uma visão holística do mundo. É justamente essa visão holística que traz potencialidades capazes de lidar com algumas das incertezas que decorrem da crise ambiental.

Para Leff (2012, p. 68), “não se consegue escapar do cerco da racionalidade econômica. O ambiente é concebido como um custo do processo econômico, não como um potencial para um desenvolvimento alternativo". O autor afirma que a questão ambiental exige reformas abrangentes que envolvem formas de pensar, 
que pedem a participação do Estado, a incorporação de normas ecológicas aos processos econômicos e o controle de externalidades.

Nascimento (2012) salienta que o atual padrão de produção e consumo não tem futuro. Para o autor:

[...] não será possível haver mudança no padrão de consumo e no estilo de vida se não ocorrer uma mudança de valores e comportamentos; uma sublimação do valor ter mais para o valor ter melhor; se a noção de felicidade não se deslocar do consumir para o usufruir; se não se verificar a transferência da instantaneidade da moda para a durabilidade do produto; se não tivermos pressões para a adoção e valorização, por exemplo, do transporte público e, se possível, para o melhor transporte, o não transporte. O desenvolvimento sustentável, aparentemente, supõe uma reforma intelectual e moral, para usar a velha expressão de Gramsci (1975), de maneira a acolher e estimular a adoção de novas tecnologias e novas formas de viver (NASCIMENTO, 2012, p. 57).

Portanto, a superação da sociedade de consumo requer a alteração das relações sociais de produção e de consumo, condição para a sustentabilidade social e ambiental.

Para Nascimento (2012), a noção de sustentabilidade tem duas origens: a ecológica e a econômica. A primeira se refere à "capacidade de recuperação e reprodução dos ecossistemas (resiliência) em face de agressões antrópicas (uso abusivo dos recursos naturais) ou naturais (terremoto, tsunami, fogo etc.)" (NASCIMENTO, 2012, p. 51). Já a segunda:

[...] como adjetivo do desenvolvimento, em face da percepção crescente ao longo do século $X X$ de que o padrão de produção e consumo em expansão no mundo, sobretudo no último quarto desse século, não tem possibilidade de perdurar. Ergue-se, assim, a noção de sustentabilidade sobre a percepção da finitude dos recursos naturais e sua gradativa e perigosa depleção (NASCIMENTO, 2012, p. 51). 
Por meio da leitura das definições apresentadas pelo autor citado, observase que a sustentabilidade pode ser pensada levando em consideração as concepções ecológicas ou administrativas, havendo variadas definições e interpretações para o termo.

Já Miller (2007, p. 3), vê a sustentabilidade como "a capacidade dos diversos sistemas da terra, incluindo as economias e sistemas culturais humanos de sobreviverem e se adaptarem às condições ambientais em mudanças". O autor reflete que o problema está na ação humana, posto "que muitas atividades humanas degradam o capital natural ao usar recursos normalmente renováveis mais rápido do que a natureza consegue renová-los" (MILLER, 2007, p. 05).

Considerando o uso dos recursos, para Leff (2012, p. 15), o "conceito de sustentabilidade surge, portanto, do reconhecimento da função de suporte da natureza, condição e potencial do processo de produção".

Essa percepção da natureza como suporte de produção é um problema. De acordo com Leff (2012, p. 432), "a sustentabilidade implica internalizar as "externalidades" econômicas na ordem da produção". Esse processo não pode ocorrer por meio da "economização" das ordens naturais e culturais, mediante a decodificação econômica e a mercantilização da natureza.

Jacobi (2003, p. 526) destaca ainda que:

[...] a ideia de sustentabilidade implica na prevalência da premissa de que é preciso definir uma limitação definida nas possibilidades de crescimento e um conjunto de iniciativas que levem em conta a existência de interlocutores e participantes sociais relevantes e ativos.

Esse autor chama a atenção para a limitação como algo que deve estar presente ao se pensar em possibilidades de crescimento, que deve levar em 
consideração as questões econômicas, ambientais e sociais, conhecidas como pilares da sustentabilidade.

Kuhlman e Farrington (2010) ressaltam que o conceito de sustentabilidade abarca três dimensões (econômica, ambiental e social) derivadas do conceito de Triple Bottom Line, criado por Elkington. Esse conceito vem da administração e busca uma forma de operacionalizar a responsabilidade social corporativa, o crescimento econômico e os cuidados com o meio ambiente.

Na sociedade capitalista, a busca da sustentabilidade leva à defesa da derivação do conceito em duas vertentes, sustentabilidade fraca e forte, dois termos criados pelo economista David Pearce e seus colegas em 1989.

No livro Economia do Meio Ambiente, organizado por May, Lustosa e Vinha (2003), há discussões referentes a essas concepções. Sustentabilidade forte e fraca são dois termos ligados a diferentes correntes de pensamento. A sustentabilidade fraca pressupõe que o capital natural pode ser substituído pelo capital produzido, em outras palavras, para essa concepção de sustentabilidade, desde que planejado tecnologicamente, não há limites para o crescimento (MAY; LUSTOSA; VINHA, 2003).

May, Lustosa e Vinha (2003, p. 7-8) definem o conceito da seguinte forma:

A ideia subjacente é a de que o investimento compensa as gerações futuras pelas perdas de ativos causadas pelo consumo e produção correntes. [...] $\mathrm{Na}$ abordagem da sustentabilidade fraca não se reconhecem, portanto, as características únicas de certos recursos naturais que, por não serem produzidos, não podem ser substituídos pela ação humana. Como consequência do argumento prévio, o consumo de capital natural pode ser irreversível, e a agregação simples com o capital produzido pode não ter sentido. 
Projética, Londrina, v. 12, n. 2, p. 39-69, agosto 2021

A definição apresentada por May, Lustosa e Vinha (2003) traz um entendimento mais ligado ao capital. Para Kuhlman e Farrington (2010, p. 3441), o capital é compreendido como "recursos renováveis produzidos pelo homem são equivalentes ao que os economistas chamam de capita", ou seja, os bens produzidos pelo homem, sem uma preocupação com o esgotamento dos recursos.

Kuhlman e Farrington (2010, p. 3443) definem sustentabilidade fraca como: "Que a próxima geração deve herdar um estoque de riqueza, compreendendo ativos criados pelo homem e ativos ambientais, não menos que o estoque herdado pela geração anterior".

Essa percepção de sustentabilidade causa alguns entendimentos contraditórios, pois os economistas veem mais liberdade na utilização dos recursos naturais, já que não são estipulados limites de utilização. Os ambientalistas, por sua vez, tendem a defender a visão de sustentabilidade forte que impõem mais limites à utilização dos recursos naturais (KUHLMAN; FARRINGTON, 2010).

Para os autores, a sustentabilidade forte consiste em "que a próxima geração herdará um estoque de ativos ambientais não menos do que o estoque herdado pela geração anterior" (KUHLMAN; FARRINGTON, 2010, p. 3443).

Essa visão apresenta algumas diferenças em relação à sustentabilidade fraca. Primeiramente, a sustentabilidade forte está relacionada à economia ecológica e sua essência está baseada no conceito de que o capital natural não pode ser substituído por outro tipo de capital. May, Lustosa e Vinha (2003) argumentam que a sustentabilidade forte tem por objetivo manter ambos os estoques de capital produzido e capital natural e o valor total do capital natural em si, no mínimo constante. 


\section{O autor prossegue afirmando que}

A economia ecológica vê o sistema econômico como um subsistema de um todo maior que o contém, impondo uma restrição absoluta à sua expansão. Capital (construído) e capital natural (recursos naturais) são essencialmente complementares. Na literatura, essa visão é referida através do conceito de sustentabilidade forte (MAY; LUSTOSA; VINHA, 2003, p. 11).

Essa visão de sustentabilidade incorpora as questões ambientais à economia e reconhece que o ambiente possui limites que, quando ultrapassados, podem causar grandes perdas. No entanto, há que se ressaltar que existem divergências e convergências entre as duas vertentes da sustentabilidade. May, Lustosa e Vinha (2003) afirmam que o desenvolvimento científico e tecnológico é essencial para ampliar a eficiência e utilização dos recursos naturais em geral, sejam eles renováveis ou não renováveis. Eis um ponto de convergência entre a sustentabilidade fraca e forte: "a convicção de que é possível instituir uma estrutura regulatória baseada em incentivos econômicos capaz de aumentar incessantemente essa eficiência" (MAY; LUSTOSA; VINHA, 2003, p. 11).

A eficiência na utilização de recursos beneficiaria não somente o empresário, mas o meio ambiente, por assegurar uma gestão eficiente deste. No entanto, há também pontos de divergência entre essas duas visões, pois "permanece, entretanto, a discordância fundamental em relação à capacidade de superação indefinida dos limites ambientais globais" (MAY; LUSTOSA; VINHA, 2003, p. 11).

Há muitos problemas em pensar a sustentabilidade e transformar a sociedade atual em uma sociedade sustentável, visto que, pensar esse conceito está relacionado às questões econômicas e produtivas e não em uma mudança global de atitudes no que se refere aos padrões de consumo e produção, assim como de estilo de vida. 
Kuhlman e Farrington (2010, p. 3444) afirmam que embora o corpo de literatura que discute e busca definir a sustentabilidade seja bastante amplo, há a necessidade de conceituar de forma mais precisa esse conceito, "uma vez que a sustentabilidade é um tema de ambos, avaliação das políticas e estudos científicos, sua definição deve ser útil para ambos os campos de trabalho".

Ainda que ciente dos problemas que envolvem a relação desenvolvimento sustentável/sustentabilidade/sociedade capitalista, faz-se necessário o trabalho com o conceito sustentabilidade forte. O conceito de sustentabilidade forte é adequado para esta reflexão, por considerar os recursos naturais como finitos e, acima de tudo, por incorporar as questões ambientais à economia. Essa incorporação permite olhar os sistemas produtivos levando em consideração as externalidades negativas e o impacto do sistema produtivo sobre o meio ambiente. Pensar a sustentabilidade exige não somente um olhar aguçado para o sistema produtivo e também de consumo, mas uma mudança de hábito em relação à forma com que produzimos e consumimos.

Pode-se dizer que promover uma mudança em relação ao desenvolvimento sustentável, mesmo com toda problemática do conceito envolvido, requer mudanças, não apenas referentes às normativas legais e à produção ou consumo, mas da sociedade como um todo, buscando posturas favoráveis ao meio ambiente, requerendo mudanças nas práticas cotidianas. A questão não é tão fácil e suscita alguns questionamentos: como promover uma mudança de hábito? As pessoas têm o conhecimento necessário sobre meio ambiente? Qual a compreensão sobre a crise ambiental? Esse conhecimento é suficiente para mudar atitudes? Após compreender a complexidade e construir um entendimento referente ao conceito de sustentabilidade daremos continuidade, relacionando esse conceito a moda. 


\section{MODA (IN)SUSTENTÁVEL}

Pensar a sustentabilidade na moda é necessário, principalmente no que se refere à escala de produção e a forma como a moda se renova, para sustentar o consumo. Amaro Neto (2011, p. 6) afirma que "a dimensão ambiental traz uma série de questões das mais sérias em termos de impactos do modelo de desenvolvimento econômico gestado ao longo do último século". Como já citado anteriormente por Leff (2012), a problemática do atual padrão de desenvolvimento nos leva a repensar os sistemas produtivos, e a pensar de que forma é possível incorporar a sustentabilidade.

Amaro Neto (2011) chama a atenção para os indicadores da crise ambiental, que se apresentam de forma a alterar os ciclos naturais do planeta como o efeito estufa, a contaminação do solo e da água entre outros. O autor apresenta uma lista relativamente extensa ao falar dos impactos ao meio ambiente provocado pelo atual estilo de vida.

Ao pensar esses impactos, a teoria de Beck (2008), sobre sociedade de risco, trata dos riscos catastróficos que podem transformar-se em perigos globais e não apenas locais, mas acima de tudo, da forma como temos reagido aos problemas, acreditando na tecnologia como solução, que em muitos casos acaba por causar outros problemas. Assim,

Das pequenas às grandes inovações, a busca da sustentabilidade impõe-se nos diversos planos: processos produtivos mais limpos e econômicos do ponto de vista dos recursos naturais; produtos igualmente inovadores em termos de novas funções e menos impacto ambiental; novas matérias-primas para produtos já conhecidos; serviços mais intensos em conhecimento para a gestão ambiental; políticas internas de administração que envolvam a educação, tecnologia e redução de gastos relacionados a matéria-prima, processos de produção e formas de organização do trabalho (AMARO NETO, 2011, p. 10). 
O autor enfatiza a real mudança não somente em alguns setores, mas uma mudança em diversas esferas da sociedade, envolvendo o setor industrial, à política, o consumo e uma nova visão referente ao meio ambiente. A busca da sustentabilidade exige uma mudança de habitus, não somente a adoção de posturas mais adequadas em diversos setores da sociedade, mas uma mudança coletiva que leve a uma reflexão mais profunda referente à crise ambiental atual.

[...] como parte de uma sociedade ecologicamente em transformação, cabe às empresas grande parcela de responsabilidade para que se alcance o desenvolvimento sustentável. Slack et al (2002) asseveram que a magnitude do impacto ambiental está diretamente relacionada a quantidade da população consumidora e ao impacto ambiental do processo produtivo ou do produto consumido por essa população (AMARO NETO, 2011, p. 16).

Embora o autor apresente a empresa como responsável por grande parcela da poluição, assim como o consumo, cabe ressaltar aqui que a empresa não é um organismo vivo independente, mas uma organização composta por seres humanos, cada um com seus ideais e formas de ver o mundo. Assim, retornamos à teoria do habitus, pois esperar mudanças da empresa requer também mudanças de comportamento e atitudes daqueles que fazem parte dela. Mudanças que vão impactar na forma de produzir e também de consumir, mas que nem sempre são compreendidas, podendo ser adotadas de formas mecânicas, porque há uma lei que as exige. Nesse sentido, Berlim (2012) aborda a responsabilidade, que não deve se entender somente às ações empresariais:

Responsabilidade para o autor (KAZAZIAN, 2005), extrapola o círculo restrito às ações empresariais já estabelecidas nos campos da responsabilidade socioambiental e se estende aos indivíduos e seus valores éticos e morais. Para ele, a responsabilidade está ligada a um agir responsável, em que o indivíduo tem consciência das consequências de suas ações e é capaz de compreender e considerar, a cada tomada de decisão, a relação de interdependência que existe entre as esferas econômicas e sociais e a biosfera (BERLIM, 2012, p. 59). 
A busca da sustentabilidade exige uma mudança de habitus, não somente a adoção de posturas mais adequadas em diversos setores da sociedade, mas uma mudança coletiva que leve a uma reflexão mais profunda referente à crise ambiental atual.

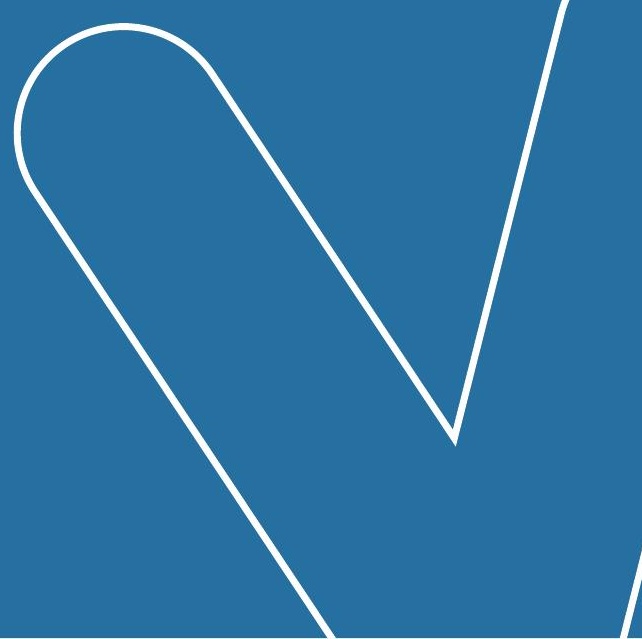


A leitura de Berlim sobre Kazazian é fundamental, uma vez que parte do princípio de que todo indivíduo tem responsabilidade sobre suas ações e que as mesmas interferem no ecossistema. Não é apenas a empresa, mas a sociedade como um todo que precisa mudar a forma de pensar e agir para se alcançar a sustentabilidade nos setores produtivos, na forma de consumo e no estilo de vida.

Essa percepção também se aplica à indústria da moda: como promover a sustentabilidade na moda? É possível alcançá-la? Berlim (2012, p. 22) ressalta que:

\begin{abstract}
O uso desses termos pela moda geralmente reduz a sustentabilidade ao uso de fibras naturais, tingimentos não poluentes, materiais orgânicos e reciclados, lojas eco eficientes, plantio de árvores, coleta e reciclagem de lixo, entre outras ações que remetam ao termo. Assim, o consumidor entende essas ações como sustentáveis e absorve a ideia de que esse conceito está relacionado apenas à ecologia e meio ambiente.
\end{abstract}

A afirmativa da autora chama a atenção para a compreensão daquilo que é a sustentabilidade. Quando pensamos nessa compreensão, surge a noção de representação social de Moscovici (2003) e os estudos desenvolvidos por Reigota (1997) relacionados à representação social e meio ambiente. Há uma forma de compreensão em relação ao que seja a sustentabilidade: o entendimento científico, que se relacionaria ao universo reificado de Moscovici e a apreensão que se tem dele, referindo-se ao universo consensual, momento em que o conceito de sustentabilidade se transforma em uma representação social.

Ao pensar essas formas de compreensão do conceito, é possível entender como o mesmo é colocado em prática e que, via de regra, é entendido como sinônimo de reciclagem ou reutilização de produtos. Em outras palavras, é excluída do seu cerne a multiplicidade de questões que ele engloba. 
Partindo desse raciocínio, surge o seguinte questionamento: como exigir mudanças de habitus se os agentes sociais não têm, no que se refere à sustentabilidade, o alcance da gravidade da crise ambiental e mesmo do que seja o meio ambiente?

A literatura voltada à discussão de moda e sustentabilidade busca contemplar alguns pontos, de maneira um tanto quanto insuficiente, mas chama a atenção para alguns pontos em específico.

No que se refere à moda, como já dito por Berlim (2012), muito se pensa em materiais que sejam menos agressivos. Outros pesquisadores que ressaltam esse aspecto são Fletcher e Grose (2011) que trazem propostas acerca do tema e sua utilização na cadeia têxtil. Contudo, esse trabalho preocupa-se mais em qualificar o que é ou não é sustentável, especificamente quando se trata de fibras, não aprofundando as questões produtivas que englobam toda a cadeia. Há, por parte das autoras, um foco na economia de energia, de água e na produção de matérias-primas consideradas limpas. São contribuições relevantes, mas pouco profundas no que se refere à sustentabilidade. Para as autoras, Fletcher e Grose (2011, p. 13).

O material usado na confecção de vestuário está associado a todo tipo de impacto sobre a sustentabilidade: mudanças climáticas, efeitos adversos sobre a água, e seus ciclos; poluição química; perda de biodiversidade; uso excessivo ou inadequado de recursos não renováveis; geração de resíduos, efeitos negativos sobre a saúde humana; e efeitos sociais nocivos para as comunidades produtoras. Todos os materiais afetam de alguma forma os sistemas ecológicos e sociais, mas esses impactos diferem de uma fibra para outra quanto ao tipo e à escala.

Esses impactos não só variam em escala e grau de intensidade durante o processo de confecção da roupa, mas continuam após o seu descarte. No caso 
Projética, Londrina, v. 12, n. 2, p. 39-69, agosto 2021

das confecções, os resíduos são formados ao longo da ação produtiva que gera diferentes subprodutos (SERVIÇO NACIONAL DE APRENDIZAGEM INDUSTRIAL, 2007), resultando em "impactos ambientais e sociais ao longo do ciclo de vida da roupa" (UNITED KINGDOM, 2010, p. 2).

Fletcher e Grose (2011, p. 12) consideram que:

Além de decisivos para a sustentabilidade, os materiais são cruciais para a moda, tornam real sua produção simbólica e nos fornecem o meio físico com o qual construir identidade e agir como seres sociais e indivíduos. Nem toda expressão de moda assume uma forma mediante fibras têxteis, mas, quando o faz, fica sujeita às mesmas leis da física e aos mesmos limites naturais finitos.

Ao pensarmos nos limites da materialidade da roupa, devemos lembrar que mesma não é apenas composta por fibras têxteis. Há, em uma peça de roupa, uma série de elementos: o tipo de fibra, os produtos químicos utilizados para tingimento e acabamento dos tecidos, a confecção na qual são incorporados novos tingimentos, estampas, bordados e aviamentos dos mais variados. Portanto, a roupa traz consigo uma carga de elementos que tornam a sua produção uma tarefa longa e complexa, se pensarmos no processo desde a obtenção da fibra aos diversos setores que dão auxílio à cadeia têxtil.

Walters, Santillo e Johnston (2005), membros do Greenpeace Research Laboratories, considera em relatório publicado em 2005, a problemática dos químicos utilizados nos processos de beneficiamento e acabamentos dos tecidos. 0 autor ressalta que não se trata de danos à água ou ao solo, mas do uso excessivo de recursos dos mais variados e da falta de cuidados no gerenciamento dos resíduos gerados. 
Para o autor, é necessário muito mais do que insumos limpos: exige-se uma mudança em todo o processo de produção e gerenciamento de resíduos e práticas mais adequadas.

Na maioria das indústrias o impacto ambiental ocorre durante a produção. O conteúdo total de substâncias de precaução elevada no produto final do vestuário é limitado e depende de processamento específico e técnicas empregadas (WALTERS; SANTILLO; JOHNSTON, 2005, p. 03).

Outros autores que contribuem acerca desta questão são Manzini, e Vezzoli (2011). Na obra O desenvolvimento de produtos sustentáveis, os autores abordam a metodologia de análise de ciclo de vida do produto para mapear seus impactos, assim como uma série de indicações referentes a como produzir produtos sustentáveis.

Nesse sentido, é necessário rever

O design ambiental do existente; o projeto de novos produtos ou serviços que substituam os atuais; O projeto de novos produtosserviços intrinsecamente sustentáveis; A proposta de novos cenários que correspondam ao estilo de vida sustentável (MANZINI; VEZZOLI, 2011, p. 20).

Os autores consideram necessário, para uma reestruturação da produção, "novos cenários que correspondam ao estilo de vida sustentável". Embora não indiquem quais seriam esses cenários, visto que tratam da produção e de produtos e serviços sustentáveis, pressupõe-se que seja o consumo e impactos em larga escala, devido à produção desses bens que, segundo os autores, são sustentáveis; mas estes seriam produtos menos impactantes ao meio ambiente.

Quando se pensa na moda e em seu sistema de produção e consumo não há a visão de sustentabilidade. Atitudes como gestão dos recursos renováveis, energia 
Projética, Londrina, v. 12, n. 2, p. 39-69, agosto 2021

e tecnologias limpas não tornam a cadeia produtiva ou o produto sustentável, mas menos impactantes.

Observamos que essas atitudes, em relação à produção, estão inseridas dentro de uma lógica capitalista, que pressupõe a produção em larga escala, o consumo e a geração de lucros. Isso nos leva a repensar o conceito de desenvolvimento sustentável. Como pensar em moda sustentável ou produtos sustentáveis se a moda sobrevive da renovação constante de tendências que estimulam o consumo e o descarte de objetos que estão fora de moda, mesmo que ainda estejam em condições de uso?

Zanirato (2013) caminha nessa direção ao considerar que moda e sustentabilidade não são compatíveis. Para a autora:

A produção em larga escala e a renovação constante de produtos se pautam na crença da abundância infinita de materiais, na possibilidade inquestionável da disponibilidade de matéria-prima e de energia para a produção, e não leva em consideração que os atuais padrões de consumo estão nas raízes da crise ambiental (ZANIRATO, 2013, p. 44).

Essa reflexão nos leva aos seguintes questionamentos: a gestão de recursos e energia, assim como tecnologias limpas, beneficia a quem? Ao meio ambiente ou à empresa? Pouco se discute em relação ao consumo, mas muito sobre produtos sustentáveis e tecnologias limpas, sem levar em consideração a reserva de recursos naturais que é finita, como afirma Zanirato (2013). “Não se pode falar em sustentabilidade sem considerar mudanças no estilo de vida, nas atitudes e comportamentos. A sustentabilidade é uma condição que aponta para o futuro, o que indica a necessidade de superação do consumo na escala atual" (ZANIRATO, 2013, p. 47). 
Essa mudança de atitude nos leva, uma vez mais, a repensar os conceitos habitus e as representações sociais que os indivíduos têm do meio ambiente. É necessário, para que haja mudanças, alterações que ultrapassem os limites dos processos produtivos e das normativas legais.

Cientistas, cientistas sociais, jornalistas e políticos preocupados com o futuro do meio ambiente afirmam que é insustentável a continuidade do nível e dos tipos de consumo hoje prevalecentes. De acordo com essa perspectiva, as economias devem crescer de maneira estável, em vez de se orientar pela maximização do crescimento. 0 consumo deve deixar de ser o motor principal do desenvolvimento econômico. [...] os ambientalistas sustentam que é necessária uma mudança importante na natureza do consumo, no sentido de que os produtos sejam produzidos de modo a proteger o ambiente e conservar os recursos, não de modo que a obsolescência dos bens de consumo seja o objetivo principal da produção e consumo dos produtos (CRANE; BUENO, 2011, p. 229).

No entanto, pensar em minimizar o consumo dentro de uma sociedade capitalista e com indivíduos ávidos por novidades mostra-se um desafio. Algumas empresas de moda estão na busca de produzir uma moda menos impactante e mais ética.

As empresas que procuram produzir roupas de modo ético têm dois objetivos importantes. O primeiro é eliminar as confecções com péssimas condições de trabalho, na produção de vestuário nos países em desenvolvimento; esse objetivo é atingido mediante o pagamento de salários razoáveis e a confecção de roupas em fábricas que constituem ambientes saudáveis. O segundo é utilizar materiais e procedimentos de produção que protejam o ambiente, em vez de destruí-lo; [...] o objetivo da moda ética não é reduzir ou eliminar o consumo de vestuário, mas substituir os bens de consumo por produtos menos prejudiciais ao ambiente, tanto social quanto materialmente (CRANE; BUENO, 2011, p. 238-239). 
As soluções apresentadas pelos autores são essenciais, mas temos que ter em vista wu o ciclo do produto de moda está ligado a renovação estética, portanto, o que precisa ser remodelado é forma de consumo que temos em nossa sociedade, visto que o mesmo é predatório em relação ao meio ambiente. Portanto, para além de minimizar impactos, é necessário fazer o redesign de produtos, mas que tenham ciclos de vida mais longos, além de buscar modos de produção alternativos.

Embora essas atitudes que visam a criação de produtos menos impactantes sejam ainda insuficientes frente à escala de produção em que a moda atua, Zanirato (2013) afirma que

Há que se ter clareza que esses procedimentos diminuem o impacto em comparação com a produção que não os emprega. Ainda assim, não se pode dizer que sejam práticas sustentáveis, uma vez que não objetivam produzir menos, mas sim produzir de outra maneira, priorizando a eficiência e ofertando artigos que estejam em sintonia com o tema ambiental, para potencializar uma evolução cada vez maior dos produtos (ZANIRATO, 2013, p. 51).

Essas práticas menos impactantes são fundamentais, mas não são suficientes frente à complexidade da problemática ambiental como afirma a autora. Como já foi dito, “moda, já sabemos, pressupõe renovação, ou seja, mudança de tempos em tempos, novos produtos, formas, cores, materiais e texturas" (ZANIRATO, 2013, p. 51). Essas mudanças e inovações fazem com que novos padrões estéticos apareçam, surgindo uma nova categoria de objetos que "estão na moda" e que incentivam o consumo e provocam o descarte de bens.

As inovações referentes aos processos produtivos são apresentadas como sustentáveis, "mas não objetivam a diminuição do consumo, com isso, permanece a pressão sobre os recursos naturais renováveis ou não, ou seja, sobre a substância 
e matéria-prima encontradas e extraídas da natureza" (ZANIRATO, 2013, p. 51). A autora prossegue afirmando que

Se o caminho para o desenvolvimento sustentável é o da materialização da sustentabilidade, ou seja, da transformação do discurso em prática, é impossível pensar em uma moda sustentável, já que o que se pretende descartável não pode ser sustentável. Como fazer isso considerando o encantamento com o novo, o fascínio pelo consumo e a pressão do mercado? (ZANIRATO, 2013, p. 54).

Encerramos nossa reflexão utilizando o questionamento de Zanirato (2013): como tornar a moda sustentável, considerando o encantamento com o novo, o fascínio pelo consumo e a pressão do mercado?

Reafirmamos, no entanto, que não enxergamos a moda como sustentável, mas objetivamos a busca constante pelo desenvolvimento de práticas que tornem seus produtos menos impactantes.

\section{CONSIDERAÇÕES FINAIS}

A moda é ou não sustentável? Esse questionamento pode ser respondido de forma negativa ou positiva dependendo dos autores e correntes teóricas. No entanto, o que nos provoca inquietações é o fato de que em muitos casos compreendemos ou lemos que a moda pode ser sustentável. Porém, ser sustentável vai muito além da reciclagem ou utilização de fibras naturais. A cadeia de produção é muito complexa e extensa e exige um olhar mais atento para essa questão. 


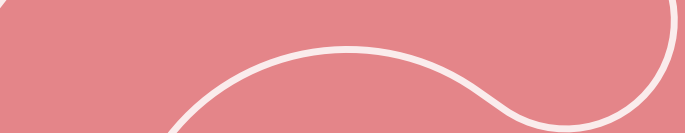

Projética, Londrina, v. 12, n. 2, p. 39-69, agosto 2021

As inovações referentes aos processos produtivos são apresentadas como sustentáveis, "mas não objetivam a diminuição do consumo, com isso, permanece a pressão sobre os recursos naturais renováveis ou não, ou seja, sobre a substância e matéria-prima encontradas e extraídas da natureza" (ZANIRATO, 2013, p. 51). 
O que objetivamos com este artigo não é desconsiderar as pesquisas já realizadas sobre esse assunto, tampouco desmerecê-los, mas, prioritariamente, levantar questionamentos sobre o assunto, provocando uma reflexão mais aguçada para que você, leitor, tire suas próprias conclusões. Primeiramente, é necessário compreender o que é moda e o que é sustentabilidade e então levantar os argumentos pelos quais consideramos a moda insustentável.

Compreendemos moda como um fenômeno de mudanças cíclicas que influencia não somente as tendências do vestuário, mas que abarca a arquitetura, carros, mobiliário, decoração, ou seja, engloba as diversas atividades produtivas e culturais na qual o design está presente; moda enquanto fenômeno que engloba diferentes setores produtivos e de consumo, bem como seus impactos sobre a sociedade e o ambiente (LIPOVETSKY, 1989).

Por sustentabilidade, entendemos ações e atividades humanas que visam suprir as necessidades atuais dos seres humanos, sem comprometer o futuro das próximas gerações. Utilizamos aqui o conceito de sustentabilidade forte que vem da economia ecológica, que considera os recursos como finitos e, acima de tudo, por incorporar as questões ambientais à economia. Essa incorporação permite olhar os sistemas produtivos levando em consideração as externalidades negativas e o impacto do sistema produtivo sobre o meio ambiente (MAY; LUSTOSA; VINHA, 2003).

Em se tratando da relação ambiente sociedade, como afirma Zanirato (2013), a moda não pode ser considerada sustentável, pois sobrevive do consumo e o incita por meio da mudança de tendências. Portanto, a moda, como um fenômeno que impacta de forma negativa o ambiente, pode apresentar práticas menos impactantes, embora não possa ser considerada sustentável. 
Projética, Londrina, v. 12, n. 2, p. 39-69, agosto 2021

Não se trata apenas de uma crítica à moda, mas ao sistema capitalista: como podemos considerar nossa sociedade sustentável se não mudamos nossa forma de consumir e viver, assim como nossas relações com o ambiente?

Se pensarmos o ambiente como finito, precisamos consumir menos e reorganizar nosso processo produtivo, como afirma Manzini e Vezzoli (2011). Desta forma, como podemos pensar em uma moda sustentável se ela sobrevive da efemeridade? Nossa resposta é bastante clara: a moda não pode ser considerada como algo sustentável, mas pode se tornar menos impactante ao ambiente por meio de adoção de práticas menos agressivas e inteligentes. 


\section{REFERÊNCIAS}

1. AMARO NETO, João. Sustentabilidade e produção: teoria e prática para uma gestão ambiental. São Paulo: Atlas, 2011.

2. BECK, Ulrich. La sociedad del riesgo mundial. Barcelona: Paidós, 2008.

3. BERLIM, Lilyan. Moda e sustentabilidade: uma reflexão necessária. São Paulo: Estação das Letras e Cores, 2012.

4. CALANCA, Daniela. História social da moda. São Paulo: Editora Senac, 2008.

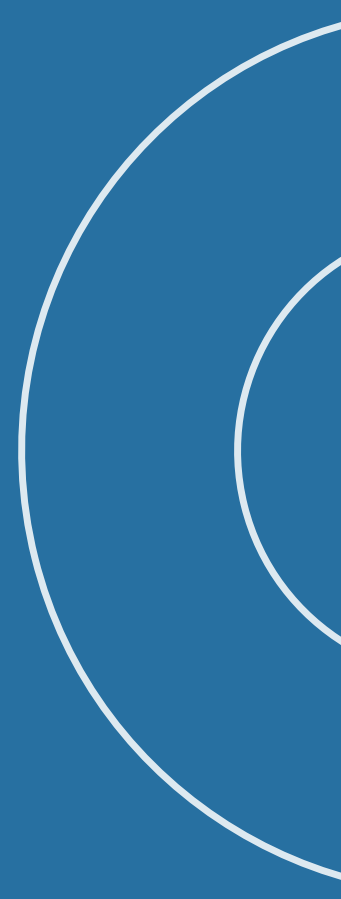

5. CRANE, Diana; BUENO, Maria Lúcia . Ensaios sobre moda, arte e globalização cultural. São Paulo: Editora Senac, 2011.

6. FLETCHER, Kate; GROSE, Lynda. Moda e sustentabilidade: design para mudança. São Paulo: Editora SENAC, 2011.

7. JACOBI, Pedro Roberto. Educação ambiental, cidadania e sustentabilidade. Cadernos de Pesquisa, São Paulo, n. 118, p. 189-205, mar. 2003. disponível em: https://www.google.com.br/url?sa=t\&rct=j\&q=\&esrc=s\&source=web\& $c d=1 \& v e d=0$ ahUKEwjKyqWCr-PLAhVGkpAKHUFWCpUQFgg9MAA\&url=http \%3A\%2F\%2Fwww.scielo.br\%2Fpdf\%2Fcp\%2Fn118\%2F16834.pdf\&usg=AFQj CNFTW6zuzpBMYhy3NjTLDTEXfqmjXQ\&sig2=hM5wr4BiRg9pUdAehL4-mQ . Acesso em: 02 maio 2020.

8. KUHLMAN, Tom; FARRINGTON, John. What is sustainability? Sustainability, [s. I.], v. 2, n. 11, p. 3436-3448, 2010. Disponível em: http://www.mdpi. com/2071-1050/2/11/3436. Acesso em: 02 maio 2020. 
Projética, Londrina, v. 12, n. 2, p.39-69, agosto 2021

9. LEFF, Enrique. Saber ambiental: sustentabilidade, racionalidade, complexidade, poder. 9. ed. Rio de Janeiro: Vozes, 2012.

10. LIPOVETSKY, Gilles. O império do efêmero: a moda e o seu destino nas sociedades modernas. Lisboa: Publicações Dom Quixote, 1989.

11. MANZINI, Ezio; VEZZOLI, Carlo. O desenvolvimento de produtos sustentáveis. São Paulo: EDUSP, 2011.

12. MAY, Peter H.; LUSTOSA, Maria Cecília; VINHA, Valéria. Economia do meio ambiente: teoria e prática. Rio de Janeiro: Elesvier, 2003.

13. MILLER, George Tyler . Ciência ambiental. São Paulo: Thomson, 2007.

14. MOSCOVICl, Serge. Representações sociais: investigação em psicologia social. Petrópolis: Vozes, 2003.

15. NASCIMENTO, E. P. do. Trajetória da sustentabilidade: do ambiental ao social, do social ao econômico. In Estudos. Avançados, vol.26, no.74. São Paulo: Editora USP, 2012

16. REIGOTA, Marcos. Meio ambiente e representação Social. 2. ed. São Paulo: Cortez. 1997.

17. SERVIÇO NACIONAL DE APRENDIZAGEM INDUSTRIAL. Departamento Regional do Rio Grande do Sul. Conselho Regional. Produção mais limpa em confecções. Porto Alegre: SENAI-RS, 2007. Disponível em: http:// wwwapp.sistemafiergs.org.br/portal/page/portal/sfiergs_senai_uos/ senairs_uo697/proximos_cursos/Produ\%E7\%E30\%20mais\%20Limpa\%20 em\%20Confec\%E7\%F5es.pdf. Acesso em: 02 maio 2020. 
18. SORCINELLI, Paolo. Estudar a moda: corpos, vestuário, estratégias. São Paulo: Editora Senac, 2008.

19. TALMASQUIM, Maurício Tiamno. Economia do meio ambiente: forças e fraquezas. In: CAVALCANTI, Clóvis (org.). Desenvolvimento e natureza: estudos para uma sociedade sustentável. 4. Ed. São Paulo: Cortez, 2003. p. 323-344.

20. UNITED KINGDOM. Department for Environment, Food and Rural Affairs. Sustainable clothing action plan. London: DEFRA, 2010. Disponível em: https://www.google.com.br/

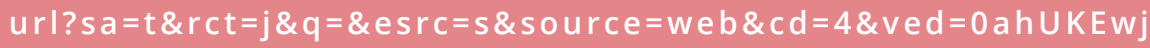
Ogf7bruPLAhUDxpAKHdzgDI8QFghJMAM\&url=https\%3A\%2F\%2Fwww.gov. uk\%2Fgovernment\%2Fuploads\%2Fsystem\%2Fuploads\%2Fattachment_ data\%2Ffile\%2F69193\%2Fpb13206-clothing-action-plan-100216.pdf\&usg=A FQjCNHmjrDV4e4MiZMI1WS0tWkBcZ-Q8g\&sig2=255ocEJelizXZF1 Pu5H7Lg. Acesso em: 02 maio 2020.

21. WALTERS, Adam; SANTILLO, David; JOHNSTON, Paul. An overview of textiles processing and related environmental concerns. Exeter: University of Exeter, 2005. Disponível em: https://greenpeace.to/publications/ textiles_2005.pdf. Acesso em: 02 maio 2020.

22. ZANIRATO, Sílvia Helena. Moda e sustentabilidade: um diálogo paradoxal? In: SIMILI, Ivana G.; VASQUES, Ronaldo S. (org.). Indumentária e moda: caminhos investigativos. Maringá: EDUEM, 2013, v. 1, p. 41-56. 